Randomized Trial

\title{
Two-Year Outcome of Percutaneous Bipolar Radiofrequency Neurotomy of Sacral Nerves S2 and S3 in Spinal Cord Injured Patients with Neurogenic Detrusor Overactivity: A Randomized Controlled Feasibility Study
}

Hae Min Jo, MD, Hyo Sung Kim, MD, Yun Woo Cho, MD, and Sang Ho Ahn, MD

From: Yeungnam University School of Medicine and College of Medicine, Korea

Address Correspondence: Sang Oh Ahn, MD Yeungnam University School of Medicine and College of

Medicine 317-1, Daemyungdong, Namku, Taegu, 705-717 KOREA E-mail: rmkhsı@daum.net

Disclaimer: This work was supported by the 2014 Yeungnam University Research Grant.

Conflict of interest: Each author certifies that he or she, or a member of his or her immediate

family, has no commercial association (i.e., consultancies, stock ownership, equity interest, patent/licensing arrangements, etc.) that might pose a conflict of interest in connection with the submitted manuscript.

Manuscript received: 12-02-2015 Accepted for publication: 02-04-2016

Free full manuscript: www.pain physicianjournal.com
Background: Little research has been expended on the use of bipolar radiofrequency (RF) lesioning of sacral nerves in spinal cord injured $(\mathrm{SCI})$ patients with neurogenic detrusor overactivity (NDO), and no study has been undertaken to demonstrate its long-term effect.

Objective: To investigated the effect of bipolar RF ablation of the second and third sacral nerves over 2 years in $\mathrm{SCl}$ patients with NDO.

Study Design: A prospective, randomized controlled feasibility study.

Setting: The outpatient clinic of a single academic medical center in Korea.

Methods: Ten SCI patients with NDO were recruited. These patients were randomly assigned to 2 groups; the intervention group $(n=5)$ and the control group $(n=5)$. Control group members received optimized conventional treatment. International Consultation on Incontinence Questionnaire (ICIQ), 3-day voiding diary, and the urinary incontinence quality of life scale (I-QOL) data were obtained at baseline and at 6, 12, and 24 months after intervention. Urodynamic study (UDS) was performed at baseline and 24 months after intervention. In the intervention group, percutaneous bipolar RF neurotomy was performed on both S2 and S3 nerves in each patient.

Results: Frequency of urinary incontinence and ICIQ and IQOL scores showed significant effects for time and for the group $x$ time interaction $(P<0.05)$. Daily mean volume of urinary incontinence showed only a significant group effect. In UDS parameters, comparisons of values at baseline and at 24 months revealed all variables showed significant intergroup differences $(P<0.05)$.

Limitation: A small number of patients was recruited.

Conclusion: Percutaneous bipolar RF ablation of sacral nerves S2 and S3 effectively reduces urinary incontinence and improves quality of life (QoL) in SCI patients with NDO and the effects lasted over 2 years.

Key words: Neurogenic detrusor overactivity, bipolar RF neurotomy, sacral nerves, urinary incontinence, maximal detrusor pressure, maximum cystometric capacity

Pain Physician 2016; 19:373-379 eurogenic detrusor overactivity (NDO) is an urodynamic observation characterized by involuntary detrusor contractions during the filling phase following a relevant neurological condition (e.g., spinal cord injury (SCI) or multiple sclerosis) (1). Associated NDO symptoms, such as urgency with or without urge incontinence, frequency, and nocturia are common complications in patients with $\mathrm{SCl}(2,3)$. 
In particular, NDO causes urinary tract infections, renal damage, sleep disturbance, depression, and reduces sexual and physical activity, and thus, lowers quality of life (QoL) (3-5). Therefore, proper management of NDO can prevent other complications in patients with $\mathrm{SCl}$, and consequently, aggressive management of NDO is required to improve QoL in patients with $\mathrm{SCl}$.

Various traditional managements have been used to relieve NDO in patients with $\mathrm{SCl}$, such as anticholinergic drugs, behavior adjustments (timed voiding, bladder retraining, pelvic floor training), and clean intermittent catheterization (CIC) $(5,6)$. However, these managements have significant limitations. Anticholinergics, the first-line medication, can have unwanted effects, such as dry mouth, memory impairment, constipation, blurred vision, and tachycardia (7). CIC can cause urinary tract infections and urethral injury (8). In addition to these conventional managements, surgical and interventional managements have been used to treat NDO, such as penile prosthesis implantation, external sphincterotomy, augmentation cystoplasty, intramuscular botulinum toxin $A$ injection, and sacral rhizotomy (5-14). Selective sacral neurotomy by radiofrequency (RF) ablation has been developed recently to increase bladder capacity and preserve detrusor reflex and sphincter function in SCI patients with NDO $(15,16)$. Little research has been expended on the use of bipolar $\mathrm{RF}$ lesioning of sacral nerves in $\mathrm{SCl}$ patients with NDO, and no study has been undertaken to demonstrate its long-term effect.

In this study, we investigated the long-term effect of bipolar RF ablation of sacral nerves S2 and S3 over 2 years in SCl patients with NDO.

\section{Methods}

\section{Patients}

Ten patients (mean age $41.2 \pm 8.01$ years [range 31 53]; 7 men) were recruited using the following inclusion criteria: (1) SCI (ASIA scale A \& B) with NDO treated for > one year; (2) age $20 \sim 70$ years; (3) no history of bladder or prostate surgery; and (4) no history of cardiovascular disease (e.g., refractory hypertension) or coagulopathy. Pregnant patients of ASIA scale C, D, or E were excluded. All patients provided written informed consent before enrollment, and institutional review board approval was obtained before commencing the study. The 10 patients were randomly assigned to either an intervention group ( 5 patients; 3 men; mean age $42.0 \pm 8.46$ years) or a control group (5 patients; 4 men; mean age $40.4 \pm 8.4$ years), members of which received conventional medical treatment.

\section{The Bipolar Radiofrequency Procedure}

The procedure was explained and discussed with the patients and informed consent was obtained. Patients were placed in the prone position and an appropriate antiseptic skin prep was performed. The fluoroscope was aligned to provide an optimal view of the S2 or S3 posterior foramen. Typically cephalad-caudad tilt was provided to square the adjacent sacral vertebral endplate. The 18 gauge cannulas used for the ablation procedure had a sharp tip with $10 \mathrm{~mm}$ exposed curved end and a total shaft length of $100 \mathrm{~mm}$. Local anesthetic was injected into the skin around the insertion site. Utilizing antero-posterior (AP) fluoroscopic guidance, the cannulas were placed through the posterior foramen and the tips spaced to encompass the expected nerve locations. Electrode position was confirmed in a lateral fluoroscopic view to not pass beyond the sacral ventral surface. Sensory nerve stimulation was then performed using a RF generator (RFG4, Cosman Medical Inc., MA, USA). During sensory nerve stimulation, paresthesia and pain or muscle contraction around the sacrum should be observed at $<0.7 \mathrm{~V}$. After placing 2 cannulas through each foramen and assuring correct position, contrast media was injected to confirm the absence of inappropriate spread. The RF lesion was created using a temp of $80^{\circ} \mathrm{C}$ for 90 seconds. The procedure was performed in this manner bilaterally at both S2 and S3 nerve segments (Fig. 1).

\section{Clinical Evaluations}

Clinical assessments were conducted using a 3-day voiding diary, the International Consultation on Incontinence Questionnaire (ICIQ), the urinary incontinence quality of life scale (I-QOL), and urodynamic study (UDS). Three-day voiding diaries are commonly used to evaluate voiding frequency and volume of urinary incontinence during the day. ICIQ is a questionnaire that evaluates the symptoms of incontinence, and its reliability and validity have been well established (17). I-QOL is a questionnaire that evaluates urinary incontinence and QoL and is known to have excellent repeatability and validity for evaluating QoL in patients with urinary incontinence $(18,19)$. In addition, UDS provides a useful means of assessing the physiological function and pathology of the lower urinary tract in patients with neurogenic bladder (20). UDS measures maximum cystometric capacity, maximum detrusor pressure dur- 


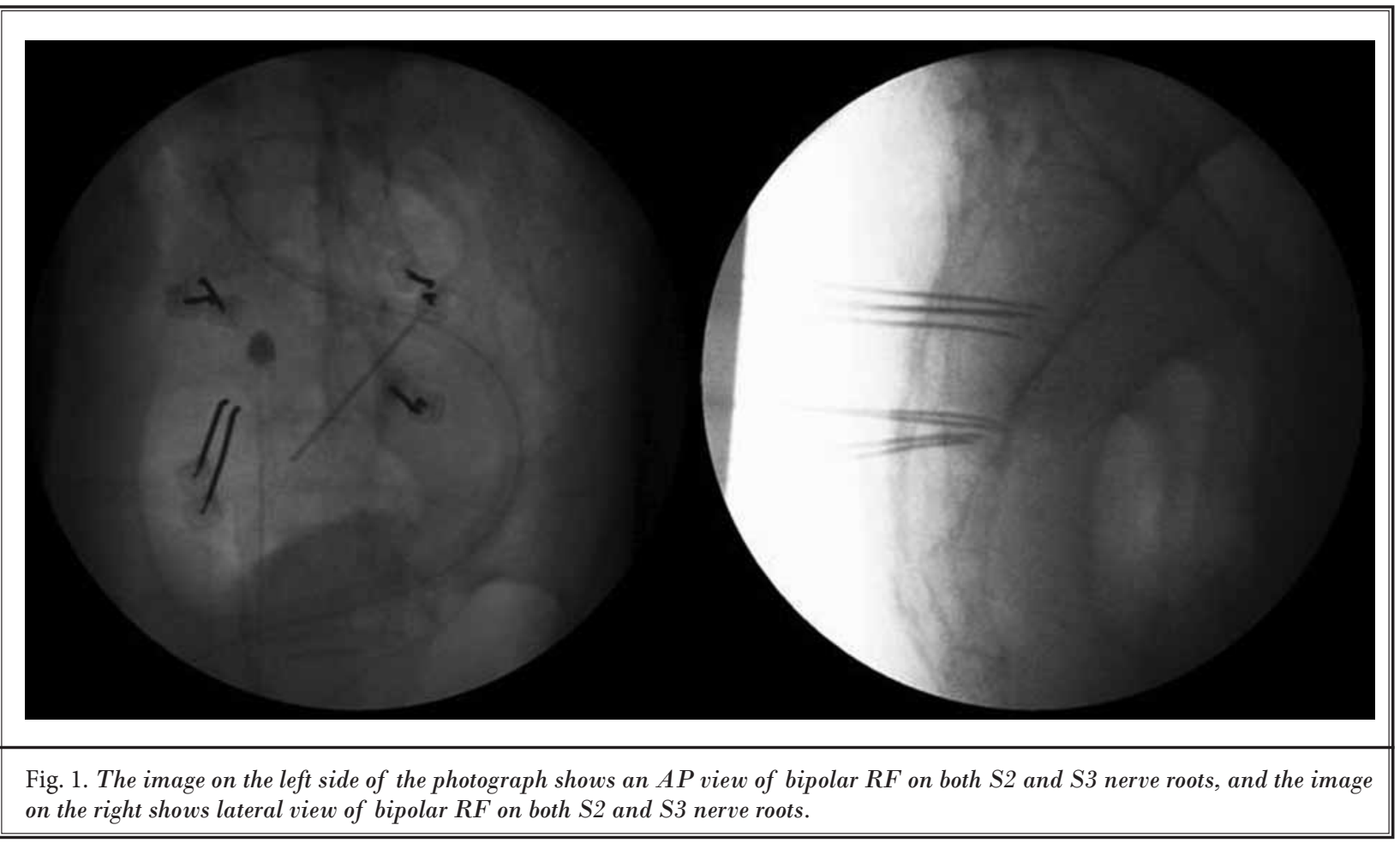

ing filling, volume at maximal detrusor pressure during filling, and reflex detrusor volume at first contraction. For UDS, the bladder was filled with normal saline at 24 $\mathrm{mL} / \mathrm{min}$ and detrusor pressure was defined as the difference between intravesical and abdominal pressure.

Patients in the intervention were assessed using the 3-day voiding diary, the ICOQ, and the I-QOL one month before the intervention (baseline) and at 6, 12, and 24 months after the intervention. Patients in the control group were also assessed using the same parameters; baseline and at 6, 12, and 24 after registration. UDS was performed one month before the intervention (baseline) and 24 months after the intervention only because of the associated risk of urinary tract infection and the risk of poor patient compliance in the intervention group. In the control group, UDS was also performed at baseline and 24 months after registration.

\section{Statistical Analysis}

SPSS software (v.19.0; SPSS, Chicago, IL, USA) was used for the analysis. Repeated measure 2 factor analysis was used to perform comparative effect analysis, as determined by clinical assessments (daily mean frequency, volume of urinary incontinence, and ICIQ and I-QOL scores) on the 2 groups. To analyze the difference between baseline and follow-up UDS parameters (maxi- mum cystometric capacity, maximum detrusor pressure during filling, volume at maximal detrusor pressure during filling, and reflex detrusor volume at first contraction), pre/post intervention differences (baseline/24 months) were calculated. The Mann-Whitney $U$ test was used to compare the 2 study groups with respect to the pre/post values of UDS parameters. Statistical significance was accepted for $P$ values $<0.05$.

\section{Results}

Table 1 summarizes the demographic and clinical data of the 10 patients, and includes baseline values for daily mean frequency and volume of urinary incontinence, ICIQ and I-QOL scores, and UDS parameters. Comparisons by time, group, and time $x$ group with respect to daily mean frequency and volume of urinary incontinence, and ICIQ and I-QOL scores at baseline and at 6, 12 and 24 months after the intervention are provided in Table 2. Frequency of urinary incontinence and ICIQ and IQOL scores showed significant effects for time and for the group $x$ time interaction $(P<0.05)$. Daily mean volume of urinary incontinence showed only a significant group effect. Values of UDS parameters at baseline and at 24-month follow-ups in both groups are shown in Table 3. Comparisons of values at baseline and at 
Table 1. Patient demographic and clinical data.

\begin{tabular}{|c|c|c|c|c|c|c|c|c|c|c|}
\hline \multirow{2}{*}{ Patient } & \multirow{2}{*}{$\begin{array}{l}\text { Age } \\
\text { /Gender }\end{array}$} & \multirow{2}{*}{$\begin{array}{l}\text { Level } \\
\text { (ASIA } \\
\text { scale) }\end{array}$} & \multirow{2}{*}{$\begin{array}{l}\text { Incontinence } \\
\text { :Frequency }\end{array}$} & \multirow{2}{*}{$\begin{array}{l}\text { Incontinence } \\
\text { :Volume }\end{array}$} & \multirow{2}{*}{ ICIQ } & \multirow{2}{*}{ I-QOL } & \multicolumn{4}{|c|}{ UDS parameters } \\
\hline & & & & & & & RDV & MDP & $\begin{array}{l}\text { V at } \\
\text { MDP }\end{array}$ & MCC \\
\hline \multicolumn{11}{|c|}{ Intervention group } \\
\hline 1 & $\mathrm{M} / 53$ & $\mathrm{C} 4(\mathrm{~A})$ & 5 & 100 & 7 & 101 & 286 & 66 & 344 & 402 \\
\hline 2 & $\mathrm{M} / 32$ & $\mathrm{C} 5(\mathrm{~B})$ & 2 & 70 & 10 & 85 & 179 & 67 & 595 & 600 \\
\hline 3 & $\mathrm{~F} / 48$ & $\mathrm{C} 4(\mathrm{~B})$ & 10 & 57 & 12 & 33 & 66 & 77 & 260 & 300 \\
\hline 4 & $\mathrm{~F} / 40$ & T6(A) & 15 & 100 & 11 & 44 & 209 & 112 & 230 & 500 \\
\hline 5 & $\mathrm{M} / 37$ & T12(A) & 6 & 95 & 18 & 28 & 253 & 78 & 180 & 360 \\
\hline \multicolumn{11}{|c|}{ Control group } \\
\hline 1 & $\mathrm{M} / 46$ & $\mathrm{C} 4(\mathrm{~A})$ & 7 & 221 & 7 & 100 & 162 & 153 & 189 & 315 \\
\hline 2 & $\mathrm{M} / 36$ & C6(A) & 2 & 125 & 10 & 37 & 215 & 48 & 298 & 400 \\
\hline 3 & $\mathrm{~F} / 31$ & $\mathrm{~T} 8(\mathrm{~A})$ & 5 & 150 & 12 & 71 & 232 & 41 & 277 & 320 \\
\hline 4 & $\mathrm{M} / 52$ & T6(B) & 2 & 120 & 12 & 91 & 49 & 50 & 101 & 275 \\
\hline 5 & $\mathrm{M} / 37$ & T11(A) & 6 & 90 & 17 & 30 & 250 & 31 & 171 & 345 \\
\hline
\end{tabular}

ASIA: American Spinal Injury Association, ICIQ: International Consultation on Incontinence Questionnaire, I-QOL: urinary incontinence quality of life scale, UDS: urodynamic study, RDV: reflex detrusor volume at first contraction, MDP: maximum detrusor pressure during filling, V: volume, MCC: maximum cystometric capacity.

Table 2. Daily mean frequency and volume of urinary incontinence and ICIQ and IQOL scores at baseline (one month before intervention) and at 6, 12 and 24 months after intervention in the 2 study groups.

\begin{tabular}{|c|c|c|c|c|c|c|c|c|}
\hline & \multicolumn{2}{|c|}{ Incontinence : Frequency } & \multicolumn{2}{|c|}{ Incontinence : Volume } & \multicolumn{2}{|c|}{ ICIQ } & \multicolumn{2}{|c|}{ I-QOL } \\
\hline & Intervention & Control & Intervention & Control & Intervention & Control & Intervention & Control \\
\hline \multicolumn{9}{|c|}{ Mean (SD) } \\
\hline Baseline & $\begin{array}{c}7.6 \\
(5.030) \\
\end{array}$ & $\begin{array}{c}4.4 \\
(2.302) \\
\end{array}$ & $\begin{array}{c}84.4 \\
(19.731) \\
\end{array}$ & $\begin{array}{c}143.2 \\
(47.657) \\
\end{array}$ & $\begin{array}{c}13.2 \\
(3.271)\end{array}$ & $\begin{array}{c}12.6 \\
(7.765) \\
\end{array}$ & $\begin{array}{c}57.8 \\
(26.167) \\
\end{array}$ & $\begin{array}{c}58.2 \\
(32.783) \\
\end{array}$ \\
\hline 6 month & $\begin{array}{c}1.8 \\
(2.168)\end{array}$ & $\begin{array}{c}4.0 \\
(2.000)\end{array}$ & $\begin{array}{c}15.0 \\
(17.321)\end{array}$ & $\begin{array}{c}137.6 \\
(105.796)\end{array}$ & $\begin{array}{c}3.6 \\
(4.099)\end{array}$ & $\begin{array}{c}11.2 \\
(5.541)\end{array}$ & $\begin{array}{c}73.8 \\
(25.203)\end{array}$ & $\begin{array}{c}55.8 \\
(24.783)\end{array}$ \\
\hline 12 month & $\begin{array}{c}1.6 \\
(2.608)\end{array}$ & $\begin{array}{c}5.2 \\
(1.483)\end{array}$ & $\begin{array}{c}19.0 \\
(26.077)\end{array}$ & $\begin{array}{c}155.4 \\
(84.293)\end{array}$ & $\begin{array}{c}3.2 \\
(5.215)\end{array}$ & $\begin{array}{c}12.4 \\
(6.465)\end{array}$ & $\begin{array}{c}72.0 \\
(23.948)\end{array}$ & $\begin{array}{c}51.8 \\
(22.466)\end{array}$ \\
\hline 24 month & $\begin{array}{c}1.6 \\
(2.302)\end{array}$ & $\begin{array}{c}4.8 \\
(1.304)\end{array}$ & $\begin{array}{c}23.0 \\
(31.937)\end{array}$ & $\begin{array}{c}156.6 \\
(86.555)\end{array}$ & $\begin{array}{c}3.4 \\
(5.273)\end{array}$ & $\begin{array}{c}12.6 \\
(6.804)\end{array}$ & $\begin{array}{c}71.2 \\
(23.973)\end{array}$ & $\begin{array}{c}51.6 \\
(22.963)\end{array}$ \\
\hline \multicolumn{9}{|c|}{ F ( $P$-value) } \\
\hline $\mathrm{T}$ & \multicolumn{2}{|c|}{$\begin{array}{c}3.866 \\
(0.003)^{*}\end{array}$} & \multicolumn{2}{|c|}{$\begin{array}{c}1.673 \\
(0.148)\end{array}$} & \multicolumn{2}{|c|}{$\begin{array}{c}8.540 \\
(0.000)^{*}\end{array}$} & \multicolumn{2}{|c|}{$\begin{array}{c}2.695 \\
(0.025)^{*}\end{array}$} \\
\hline G & \multicolumn{2}{|c|}{$\begin{array}{c}3.537 \\
(0.097)\end{array}$} & \multicolumn{2}{|c|}{$\begin{array}{c}12.749 \\
(0.007)^{\star}\end{array}$} & \multicolumn{2}{|c|}{$\begin{array}{c}5.375 \\
(0.049)^{\star}\end{array}$} & \multicolumn{2}{|c|}{$\begin{array}{c}1.204 \\
(0.304) \\
\end{array}$} \\
\hline $\mathrm{TxG}$ & \multicolumn{2}{|c|}{$\begin{array}{c}4.747 \\
(0.001)^{*}\end{array}$} & \multicolumn{2}{|c|}{$\begin{array}{c}2.015 \\
(0.082)\end{array}$} & \multicolumn{2}{|c|}{$\begin{array}{c}6.951 \\
(0.000)^{*}\end{array}$} & \multicolumn{2}{|c|}{$\begin{array}{c}4.690 \\
(0.001)^{*}\end{array}$} \\
\hline
\end{tabular}

*: Statistically significant with $P<0.05$

T: Time, G: Group. SD: Standard Deviation, ICIQ: International Consultation on Incontinence Questionnaire, I-QOL: urinary incontinence quality of life scale. 
Table 3. Urodynamic study data at baseline (one month before intervention) and at 24 months after intervention and pre/post intervention differences between the 2 groups.

\begin{tabular}{|c|c|c|c|c|c|c|c|c|}
\hline \multirow[t]{2}{*}{ Variable } & \multicolumn{2}{|c|}{$\begin{array}{l}\text { Reflex detrusor volume } \\
\text { at first contraction }(\mathrm{mL})\end{array}$} & \multicolumn{2}{|c|}{$\begin{array}{c}\text { Maximum detrusor } \\
\text { pressure during filling } \\
(\mathrm{cmH20})\end{array}$} & \multicolumn{2}{|c|}{$\begin{array}{c}\text { Volume at maximal } \\
\text { detrusor pressure during } \\
\text { filling }(\mathrm{mL})\end{array}$} & \multicolumn{2}{|c|}{$\begin{array}{c}\text { Maximum cystometric } \\
\text { capacity }(\mathrm{mL})\end{array}$} \\
\hline & Intervention & Control & Intervention & Control & Intervention & Control & Intervention & Control \\
\hline Baseline & $198.6(84.7)$ & $\begin{array}{c}181.6 \\
(81.09)\end{array}$ & $80.0(18.72)$ & $\begin{array}{c}64.6 \\
(49.97)\end{array}$ & $321.8(163.92)$ & $\begin{array}{c}207.2 \\
(163.9)\end{array}$ & $432.4(118.67)$ & $\begin{array}{c}331.0 \\
(46.02)\end{array}$ \\
\hline $24 \mathrm{M}$ & $281.6(46.51)$ & $211(35.24)$ & $63.2(15.22)$ & $\begin{array}{c}78.6 \\
(21.05)\end{array}$ & $341.4(51.60)$ & $\begin{array}{c}241.2 \\
(53.56)\end{array}$ & $467.8(45.14)$ & $\begin{array}{c}347.8 \\
(37.04)\end{array}$ \\
\hline $\begin{array}{l}\text { Pre/post values } \\
\text { (Baseline/24M) }\end{array}$ & 82.4 (76.79) & $-3.6(5.86)$ & $-16.4(13.18)$ & $7.4(14.52)$ & $81.6(78.62)$ & $7.2(2.68)$ & $70.4(46.19)$ & $\begin{array}{c}-6.2 \\
(14.04)\end{array}$ \\
\hline \multicolumn{9}{|l|}{$\mathrm{Z}(P$-value $)$} \\
\hline Baseline/24M & \multicolumn{2}{|c|}{$-2.627(\mathbf{0 . 0 0 9})^{*}$} & \multicolumn{2}{|c|}{$-2.193(\mathbf{0 . 0 2 8})^{*}$} & \multicolumn{2}{|c|}{$-2.627(\mathbf{0 . 0 0 9})^{\star}$} & \multicolumn{2}{|c|}{$-2.193(\mathbf{0 . 0 2 8})^{*}$} \\
\hline
\end{tabular}

Values represent means (SDs); SD, standard deviation; $\mathrm{M}$, months

24 months revealed all variables showed significant intergroup differences $(P<0.05)$.

\section{Discussion}

Selective sacral neurotomy by RF ablation has been utilized to increase bladder capacity and preserve detrusor reflex and sphincter function in $\mathrm{SCl}$ patients with NDO $(15,16)$. RF ablation is an effective interventional treatment that ablates nerves by generating a controlled region of heated tissue around a metal cannula's uninsulated tip which is positioned in close proximity to neural tissue. Several previous studies have reported selective sacral neurotomy using monopolar $\mathrm{RF}$ in patients with neurogenic bladder $(13,21,22)$. Ferreira et al (16) demonstrated that sacral neurotomy using percutaneous monopolar RF effectively increased maximal cystometric capacity and reduced detrusor pressure at maximal cystometric capacity in patients with hyperactive neurogenic bladder. Subsequently, Cho and Lee (15) reported that percutaneous mono-polar RF sacral neurotomy improved bladder capacity and urinary incontinence in $\mathrm{SCl}$ patients with intolerable neurogenic bladder. In these studies the sacral nerve neurotomy was performed using a monopolar RF technique. Monopolar RF heat lesioning has been widely used in neurosurgery and for pain management. It has been proposed that bipolar RF may be more effective than monopolar RF. Monopolar RF generates a prolate spheroid lesion around the uninsulated cannula tip using a distant current return "grounding" electrode. Bipolar RF generates a lesion between and around 2 closely positioned uninsulated cannula tips. It is proposed that bipolar RF may produce denser electrical fields, faster tissue heating, and larger lesions (23-25).
In a preliminary study, we investigated the shortterm effects (over 3 months) of bipolar RF neurotomy at $80^{\circ} \mathrm{C}$ for 90 seconds on sacral S2 and S3 nerves to treat NDO in SCl patients. We found that patients in the intervention group exhibited improvements in bladder capacity and had less urinary incontinence (26). This preliminary study raised questions regarding the longer term effects of bipolar RF neurotomy, and thus, in the present study, we investigated the effects of bipolar RF neurotomy on sacral nerves over a 2 year period. In our preliminary study, improvements of ICIQ and IQOL scores and daily mean frequency of urinary incontinence were found in the intervention group as compared with the control group with respect to time and time $x$ group $(P<0.05)$. In the present study, these variables also showed significant improvements $(P<$ $0.05)$, which indicates the effects of bipolar RF lesioning last for at least 2 years. In contrast, although daily mean volume of urinary incontinence in the intervention group also showed improvement in the present study, this lacked significance, which we attribute to the small number of patients enrolled. On the other hand, all UDS variables achieved significant intergroup differences at 24 months $(P<0.05)$. However, only volume at maximal detrusor pressure during filling and reflex detrusor volume at first contraction showed a significant intergroup difference between baseline and 3 months. We believe that while the beneficial effect of RF neurotomy continued over 2 years in the intervention group, urinary symptoms worsened in the control group. In fact, 4 of the 5 patients in the intervention group reduced anticholinergic usage after the intervention and continued to take anticholinergics at these reduced levels over the 2 year study period. On the other 
hand, all 5 patients in the control group added another anticholinergic drug or increased medication intake. Furthermore, a significant intergroup difference was observed at 24 months. To the best of our knowledge, this is the first study to investigate the long-term effect of bipolar RF ablation on sacral nerves in $\mathrm{SCl}$ patients with NDO.

Bipolar RF neurotomy of the S2 and S3 nerves appears to be a safe treatment option. During and after the intervention, no serious complications, such as cannula insertion site infection, were encountered. Two men in the intervention group commented on a slight reduction of penial rigidity, and thus, sometimes used sildenafil citrate. In addition, some patients reported discomfort around the intervention site for a few days after the procedure. Furthermore, bipolar RF neurotomy of S2 and S3 nerves is more cost-effective than other treatment options, such as sacral neuromodulation and intravesical botulinum toxin A injection. Over the 2-year study period, the cost of sacral neuromodulation including sacral nerve stimulation was $\$ 15,743$ and the cost of intravesical botulinum toxin $A$ injection was
$\$ 4,392$, while the cost of bipolar RF neurotomy of S2 and S3 was $\$ 300 \sim 400$ (27). It would seem that bipolar RF sacral neurotomy is likely the more cost-effective therapy for $\mathrm{SCl}$ patients with NDO.

In conclusion, we found percutaneous bipolar RF ablation of sacral nerves S2 and S3 effectively reduced urinary incontinence and improved QoL in SCl patients with NDO and that its effects lasted at least 2 years. Percutaneous bipolar RF neurotomy is also a relatively safe, cost-effective, repeatable, minimally invasive procedure, and thus we consider it one of the more favorable treatment options for SCl patients with NDO. The obvious limitation of the present study is the small number of patients recruited, and by the use of only 2 UDS evaluations per patient. Therefore, we suggest further study be undertaken on a larger number of patients with more frequent follow-up evaluations.

\section{Acknowledgments}

This work was supported by the 2014 Yeungnam University Research Grant.

\section{References}

1. Abrams P, Cardozo L, Fall M, Griffiths D, Rosier $\mathrm{P}$, Ulmesten $\mathrm{U}$, van Kerrebroeck $P$, Victor A, Wein A. The standardisation of terminology of lower urinary tract function: Report from the Standardisation Sub-committee of the International Continence Society. Neurourol Urodyn 2002; 21:167-178.

2. Herschorn S, Gajewski J, Ethans K, Corcos J, Carison K, Bailly G, Bard R, Valiquette L, Baverstock R, Carr L, Radomski S. Efficacy of botulinum toxin A injection for neurogenic detrusor overactivity and urinary incontinence: A randomized, double-blind trial. J Urol 2011; 185:2229-2235.

3. Hansen RB, Biering-Sørensen F, Kristensen JK. Urinary incontinence in spinal cord injured individuals 10-45 years after injury. Spinal Cord 2010; 48:27-33.

4. Hicken BL, Putzke JD, Richards JS. Bladder management and quality of life after spinal cord injury. Am J Phys Med Rehabil 2001; 80:916-922.

5. $\mathrm{Ku} \mathrm{JH}$. The management of neurogenic bladder and quality of life in spinal cord injury. BJU Int 2006; 98:739-745.

6. Cameron AP. Pharmacologic therapy for the neurogenic bladder. Urol Clin North
Am 2010; 37:495-506.

7. Lieberman JA 3rd. Managing anticholinergic side effects. Prim Care Companion J Clin Psychiatry 2004; 6:20-23.

8. Wyndaele JJ. Complications of intermittent catheterization: Their prevention and treatment. Spinal Cord 2002; 40:536-541.

9. Patki PS, Hamid R, Arumugam K, Shah PJ, Craggs M. Botulinum toxin-type A in the treatment of drug-resistant neurogenic detrusor overactivity secondary to traumatic spinal cord injury. BJU Int 2006; 98:77-82.

10. Giannantoni A, Mearini E, Del Zingaro M, Porena M. Six-year follow-up of botulinum toxin $A$ intradetrusorial injections in patients with refractory neurogenic detrusor overactivity: Clinical and urodynamic results. Eur Urol 2009; 55:705-711.

11. Rockswold GL, Bradley WE, Chou SN. Differential sacral rhizotomy in the treatment of neurogenic bladder dysfunction. Preliminary report of six cases. J Neurosurg 1973; 38:748-754.

12. Young B, Mulcahy JJ. Percutaneous sacral rhizotomy for neurogenic detrusor hyperreflexia.] Neurosurg 1980; 53:85-87.

13. Toczek SK, McCullough DC, Gargour
GW, Kachman R, Baker R, Luessenhop AJ. Selective sacral rootlet rhizotomy for hypertonic neurogenic bladder.] Neurosurg 1975; 42:567-574.

14. Van Kerrebroeck PE, Koldewijn EL, Rosier PF, Wijkstra H, Debruyne FM. Results of the treatment of neurogenic bladder dysfunction in spinal cord injury by sacral posterior root rhizotomy and anterior sacral root stimulation. J Urol 1996; 155:1378-1381.

15. Cho KH, Lee SS. Radiofrequency sacral rhizotomy for the management of intolerable neurogenic bladder in spinal cord injured patients. Ann Rehabil Med 2012; 36:213-219.

16. Ferreira RS, Levi d'Ancona CA, DantasFilho VP, Rodriques Netto N Jr, Miyaoka R. Percutaneous radiofrequency sacral rhizotomy in the treatment of neurogenic detrusor overactivity in spinal cord injured patients. Actas Urol Esp 2011; 35:325-330.

17. Avery K, Donovan J, Peters TJ, Shaw C, Gotoh M, Abrams P. ICIQ: A brief and robust measure for evaluating the symptoms and impact of urinary incontinence. Neurourol Urodyn 2004; 23:322-330. 
18. Oh SJ, Park HG, Lim SH, Hong SK, Martin ML, Ting BL. Translation and linguistic validation of Korean version of the incontinence quality of life (I-QoL) instrument. J Korean Continence Society 2002; 6:10-23.

19. Wagner $\mathrm{TH}$, Patrick DL, Bavendam TG, Martin ML, Buesching DP. Quality of life of persons with urinary incontinence: Development of a new measure. Urology 1996; 47:67-72.

20. Van Leijsen SA, Kluivers KB, Mol BW, Broekhuis SR, Milani FL, van der Vaart $\mathrm{CH}$, Roovers JP, Bongers MY, den Boon J, Spaans WA, de Leeuw JW, Dietz V, Kleinjan JH, Brölmann HA, Roos EJ, Schaafstra J, Heesakkers JP, Vierhout ME. Protocol for the value of urodynamics prior to stress incontinence surgery (VUSIS) study: A multicenter randomized controlled trial to assess the cost effectiveness of urodynamics in women with symptoms of stress urinary incontinence in whom surgical treatment is considered. BMC Womens Health 2009; 9:22.

21. Houle AM, Vernet O, Jednak R, Pippi Salle JL, Farmer JP. Bladder function before and after selective dorsal rhizotomy in children with cerebral palsy. J Urol 1998; 160:1088-1091.

22. Brindley GS. The first 500 patients with sacral anterior root stimulator implants: General description. Paraplegia 1994; 32:795-805.

23. Cosman ER, Nashold BS, OvelmanLevitt J. Theoretical aspects of radiofrequency lesions in the dorsal root entry zone. Neurosurgery 1984; 15:945-950.

24. Cosman ER, Jr., Cosman ER, Sr. Electric and thermal field effects in tissue around radiofrequency electrodes. Pain Med 2005; 6:405-424.

25. Cosman ER, Jr., Gonzalez CD. Bipolar radiofrequency lesion geometry: Implications for palisade treatment of sacroiliac joint pain. Pain Pract 2011; 11:3-22.

26. Kim JH, Ahn SH, Cho YW, Kwak SG, Kim HS. Short term effect of percutaneous bipolar continuous radiofrequency on sacral nerves in patients treated for neurogenic detrusor overactivity after spinal cord injury: A randomized controlled feasibility study. Annals of Rehabil Med 2015; 39:1-8.

27. Siddiqui NY, Amundsen CL, Visco AG, Myers ER, Wu JM. Cost-effectiveness of sacral neuromodulation versus intravesical botulinum $A$ toxin for treatment of refractory urge incontinence. J Urol 2009; 182:2799-2804. 
